\title{
BFI Fatigue Interference Likert Scale
}

National Cancer Institute

\section{Source}

National Cancer Institute. BFI Fatigue Interference Likert Scale. NCI Thesaurus. Code C120421.

A scale for the subjective scoring of fatigue interference that ranges from 0: Does Not Interfere to 10: Completely Interferes. 